\title{
Role of dietary fatty acids in microglial polarization in Alzheimer's disease
}

\author{
Smita Eknath Desale ${ }^{1,2}$ and Subashchandrabose Chinnathambi $i^{1,2^{*}}$ (D)
}

\begin{abstract}
Microglial polarization is an utmost important phenomenon in Alzheimer's disease that influences the brain environment. Polarization depends upon the types of responses that cells undergo, and it is characterized by receptors present on the cell surface and the secreted cytokines to the most. The expression of receptors on the surface is majorly influenced by internal and external factors such as dietary lipids. Types of fatty acids consumed through diet influence the brain environment and glial cell phenotype and types of receptors on microglia. Reports suggest that dietary habits influence microglial polarization and the switching of microglial phenotype is very important in neurodegenerative diseases. Omega-3 fatty acids have more influence on the brain, and they are found to regulate the inflammatory stage of microglia by fine-tuning the number of receptors expressed on microglia cells. In Alzheimer's disease, one of the pathological proteins involved is Tau protein, and microtubuleassociated protein upon abnormal phosphorylation detaches from the microtubule and forms insoluble aggregates. Aggregated proteins have a tendency to propagate within the neurons and also become one of the causes of neuroinflammation. We hypothesize that tuning microglia towards anti-inflammatory phenotype would reduce the propagation of Tau in Alzheimer's disease.
\end{abstract}

Keywords: Fatty acids, Omega-3 fatty acids, Tau phagocytosis, Tau inflammation, Tauopathy, Tau spreading, Microglial polarization

\section{Background}

Gliosis is a consequence of aberrant activation of microglia and astrocytes that is marked with increased expression of pro-inflammatory cytokines, leading to neuroinflammation. Microglia specifically have two phenotypes: pro-inflammatory and anti-inflammatory; this polarization of microglia depends upon the type of secreted cytokines and markers that they express on the cell surface. This polarization of microglia is influenced by many internal and external factors including dietary fatty acids. Omega-3 fatty acids especially have beneficial effects on the brain and effectively regulate microglial polarization, which is based on the type of lipid mediators they regulate. In this study, we infer that the neuroinflammatory reaction during Alzheimer's disease could be regulated by dietary intake of fatty acids, which can also enhance microglia polarization towards the

\footnotetext{
* Correspondence: s.chinnathambi@ncl.res.in

${ }^{1}$ Neurobiology Group, Division of Biochemical Sciences, CSIR-National

Chemical Laboratory, Dr. Homi Bhabha Road, Pune 411008, India

${ }^{2}$ Academy of Scientific and Innovative Research (AcSIR), Pune 411008, India
}

anti-inflammatory phase. Tau protein, on the other side, has the ability to aggregate, accumulate in neurons, and also show the ability to propagate within the neuron similar to prion-like diseases. In this study, we hypothesize that polarizing microglia with dietary fatty acids can reduce the propagation of Tau.

\section{Neurodegeneration and Tauopathies}

Progressive neuronal loss is the most commonly known hallmarks of neurodegeneration. The neuronal loss is a consequence of the accumulation of abnormal protein, defects in neurotransmitter receptors, and alteration in signaling pathways, which ultimately leads to progressive loss of structure and function of a neuron, including death of neurons $[1,2]$. Progressive neuronal loss affects the number of neuron and neuronal connections and increases complexity in a neuronal network $[1,3]$. In neurodegeneration, synaptic loss is primarily spotted due to lost neuronal connections and deposition of aberrant proteins. Neuronal loss majorly leads to dementia, which is a major consequence of Alzheimer's disease (AD),

(c) The Author(s). 2020 Open Access This article is distributed under the terms of the Creative Commons Attribution 4.0 International License (http://creativecommons.org/licenses/by/4.0/), which permits unrestricted use, distribution, and 
Parkinson's disease (PD), Huntington's disease (HD), and other neurodegenerative diseases. Memory loss and cognitive impairments are the main pathological symptoms along with physiological impairments such as difficulties in speaking and breathing and affecting body movement in the later stages of the disease [4, 5]. Changes in neuronal numbers and loss of neuronal connection are the main reason for fluctuations in behavior. These fluctuations are reversible and can be overcome by the enhancement of neuronal plasticity $[6,7]$. The accumulation of aberrant proteins amyloid- $\beta$ plaques and neurofibrillary tangles of Tau are the main reasons for neuronal network loss in many neurodegenerative diseases. Switching to alternative neuronal connection is the way to overcome this loss, which depends upon the plasticity of the brain [8]. The consistent failure of neuronal connections is responsible for daily fluctuations in behavior, and they are interconnected with the accumulation of plaques and tangles, which in turn cause neuronal loss and network dysfunction $[9,10]$.

In Alzheimer's disease, the synaptic loss is prominent due to the accumulation of $A \beta$ protein in synapses, which affect neurotransmission and thus ultimately cause neuronal loss. Tau, a microtubule-associated protein, is a vital component of intracellular neurofibrillary tangles (NFTs) in neurodegenerative diseases specially Tauopathies including AD. In the hyperphosphorylated state, which is predominant in $\mathrm{AD}$, Tau loses its native conformation and accumulates in the cell in the form of misfolded protein. These misfolded, aggregated forms of Tau then bundle up to form NFTs [11, 12]. Excessive accumulation of NFTs causes neuronal death and results in neurodegeneration $[12,13]$. Accumulation of $A \beta$ also triggers phosphorylation of Tau leading to NFT formation and enhances Tau-mediated cytotoxicity [14]. Due to hyperphosphorylation, Tau disrupts from microtubule filaments affecting the axonal stability, and Tau bundles up to form NFTs; accumulation of this leads to death of neurons, which prevails neurodegeneration $[12,15,16]$. Along with the accumulation of aberrant proteins, glial cells mainly astrocytes and microglia play a major role in impairing neuronal network. Aberrant activation of glial cells due to the presence of aberrant proteins in the brain environment causes inflammation and neuronal death $[10,17,18]$.

\section{Neuroinflammation mediated by microglia}

Microglia is being a resident immune cell of the brain, involved in surveillance and neuroprotection. Microglia have the ability to migrate, sense the environment, and phagocytose cellular debris, accumulated abnormal pathoproteins, and pathogens [19]. Microglia population predominate the brain environment depending upon the phenotype, i.e., M1 or M2. On immune challenge, microglia primarily undergoes classical activation showing inflammatory response and acts as a first line of defense to destroy the invaded pathogens. The classical activation is followed by the initiation of alternative antiinflammatory response to repair the wound and tissue damage $[20,21]$. The resident non-activated microglia occurs in ramified morphology with the long extension; however, on activation, they tend to retract the extensions and become amoeboid. The morphology change is necessary for the further migration of microglia towards the site of lesion or injury. The conventional knowledge of the brain as an immune-privileged site has been eliminated since the discovery of homeostatic microglia that constantly carry out the immune surveillance. Specific receptors such as P2RY12 mediate the homeostatic nature of microglia [22]. The classical activation is primarily followed by IFN- $\gamma$, whereas the alternative activation is by IL-4-mediated immune response [23]. Conventionally, the microglia undergoes classical activation bearing pro-inflammatory response and has been termed as M1 microglia and the alternative activation as M2 microglia that possess anti-inflammatory response. The initial M1/ M2-derived nomenclature was assessed to purified stimuli given in in vitro conditions [24]. The single-cell RNA-sequence analysis of microglia suggested a converged expression of M1 and M2 markers due to the influence of disease-related inflammatory process. Hence, the recent studies suggest the nomenclature of M1/M2 as "M1-like" or "M2-like phenotype" based on gene expression profile $[24,25]$. The nomenclature has been changed since arresting microglia in a particular phenotype is difficult owing to their plastic nature; the cytokine changes in the environment would switch the phenotype of microglia [26].

M2 anti-inflammatory phenotype is classified as M2a, M2b, and M2c [27]. In M2 alternative activation, M2a is related to repair and regeneration, M2b transitional state is involved in immune response, whereas M2c state is involved in neuroprotection and release of antiinflammatory cytokines [28]. The newly introduced subtype of microglia named as disease-associated microglia (DAM) possess increased phagocytic ability, antigen presentation and induces clearance of aggregated proteins in neurodegeneration. The myeloid lineage-specific protein TREM-2 regulates important checkpoints and gene expression required for the DAM expression [29, 30].

On classical activation, microglia secretes proinflammatory cytokine TNF- $\gamma$, IL- $1 \beta$, TNF- $\alpha$, and IL-6 as well as reactive oxygen species (ROS), nitric oxide $(\mathrm{NO})$, and other immunomodulatory factors causing inflammatory response at the site of injury [17, 31, 32] [33]. Microglia can show alternative response by secreting anti-inflammatory cytokines such as TGF- $\beta$, IL-4, 
and IL-10, helping in tissue remodeling, repair, and increase of phagocytosis [33-36]. However, there is a very thin differential line between pro-inflammatory and antiinflammatory phenotype of microglia; hence, characterizing the particular phenotypic population in the brain environment is very critical [24]. In AD condition, proinflammatory microglia pre-dominates antiinflammatory, which impairs the healing mechanism and increases the neuroinflammation [17]. Prolonged activation of microglia at the site of the lesion would increase excessive production of pro-inflammatory cytokines, which causes the death of neurons due to inflammation and also increases the accumulation of toxic proteins [37]. This excessive cytokine secretion increases Tau hyperphosphorylation in $\mathrm{AD}$. In $\mathrm{AD}$, the accumulation of abnormal $A \beta$ peptide in synapses activates the microglia and enhances classical activation. The secreted proinflammatory cytokines by microglia may act in autocrine or paracrine mode, which also drives astrocytes activation; this cumulatively enhances neuroinflammation. Gliosis imparts synapse loss and hence increases neuronal dysfunction increasing neurodegeneration [37, 38]. Along with the accumulated $A \beta$, Tau also enhances the activation of inflammatory pathway by inducing inflammasome, IL-1 $\beta$, and increased expression of NF- $\mathrm{kB}$ pathway $[39,40]$. In this process, propagation of Tau species is mediated by insoluble aggregated form, which includes oligomers and NFTs [41, 42]. Of interest, oligomeric species of Tau play a vital role in propagation. This seeding effect of Tau is an early indication of Tauopathies and neurodegeneration, and it also has the potency to trigger activation of glia which gives rise to the inflammatory phase [12, 43-45]. The activation of microglia and its inflammatory cytokines again causes phosphorylation of Tau and increases its misfolding [38, 46-49]. Inflammation-induced Tau phosphorylation is a well-known phenomenon, where the pro-inflammatory cytokines secreted especially IL- $1 \beta$ drive phosphorylation of Tau through p-38 MAPK activation [50]. Microglial activation occurs through LPS treatment as studied by marked increase in IL-1 $\beta$ secretion and LPS-induced hyperphosphorylation of Tau by activating CDK-5 (cyclin-dependent kinase) and GSK-3 $\beta$ (glycogen synthase kinase-3ß), which are well-known kinases to be involved in hyperphosphorylation of Tau in pathological conditions [46]. Another pro-inflammatory cytokine TNF- $\alpha$ (tumor necrosis factor- $\alpha$ ) induces Tau phosphorylation at specific epitope pT231, a pretangle-associated epitope [51], whereas on the secretion of IFN- $\gamma$, which is released on viral infection, causes dephosphorylation of Tau occurring at pretangle-related epitopes [52]. All the evidences denote that Tau pathology associated with inflammation depends on the type of pro-inflammatory response.

\section{Effect of fatty acids on microglia}

Differential expression of microglial receptors and cytokines decides the type of response in brain environment. In Alzheimer's disease, extracellular senile plaques and intracellular neurofibrillary tangles are prevalent along with the inflammatory conditions due to activated microglia and astrocytes [53-55]. Therapeutic strategies can be designed to enhance microglia towards phagocytic anti-inflammatory phenotype, which has the capability to clear the debris and other pathogens to reduce the consequences of $\mathrm{AD}[17,35,56,57]$. Out of all organs, the brain has a maximum content of cholesterol as high as $25 \%$ of entire body cholesterol. Hence, cholesterol and fatty acids are most important for brain homeostasis as they are an important component of the cell membrane and maintain neuronal plasticity $[58,59]$. Dietary fatty acids consumed are reported to cross the blood-brain barrier and hence affect the brain in different aspects [60]. In addition, the presence of fatty acids in myelin sheath also plays an important role in tuning the metabolism of the brain cells mainly by microglia cells. The dietary intake of fatty acids majorly affects the response of microglia cells in the brain. Recent reports suggest that high-fat diet induces inflammatory conditions in the brain mainly in the hypothalamic region [61-63]. Saturated fatty acids increase the proinflammatory phenotype of microglia, whereas unsaturated fatty acids influence the anti-inflammatory phenotype in microglia (Fig. 1). To decrease the adverse inflammatory condition in $\mathrm{AD}$, created by microglia, one of the therapeutic strategies is the supplementation of dietary fatty acids [64]. Fatty acids act as an important metabolic mediator and a rich source of energy; however, excessive consumption of saturated fatty acids generates inflammation in body tissues as well as in the brain [64]. Inflammatory conditions occur due to the accumulation of a large number of macrophages at the sites of infection, which leads to excessive production of inflammatory cytokines. Similarly in the brain, excessive intake of saturated fatty acids (palmitic acid, stearic acid, etc.) promotes the proinflammatory phenotype of microglia [65]. It affects NF-kB pathway, TLR-4 receptors, interferon- $\gamma$ (IFN- $\gamma$ ), and tumor necrosis factor- $\alpha$ (TNF$\alpha$ ), which are the key factors of inflammatory reaction and therefore control the inflammation in the brain [31]. LPS-mediated activation of NF- $\mathrm{KB}$ pathway is a wellknown mechanism for inflammatory response [33, 66]. Saturated fatty acids mainly palmitic acid and stearic acids mimic the LPS-induced activation of NF- $\mathrm{KB}$ pathway, and reports suggest that this activation is through TLR-4 receptors. Saturated fatty acids act as a ligand for TLR-4 receptors mimicking the LPS and hence activate microglia with increased production of proinflammatory cytokines (IL- $1 \beta$, IL-6, TNF- $\alpha$ ), ROS, and 


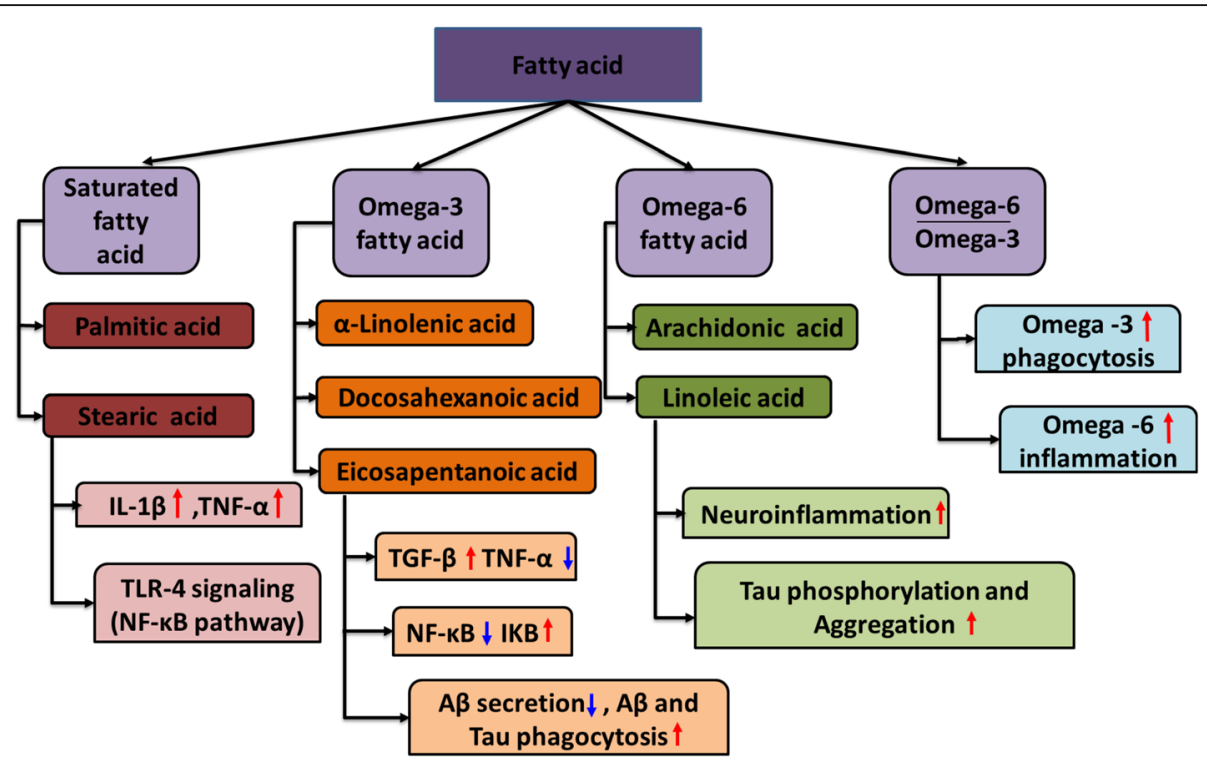

Fig. 1 Overview of fatty acids affecting inflammatory and phagocytic pathways. AD is associated with the presence of A $\beta$, neurofibrillary tangles of Tau protein, and excessive accumulation of glia cells, which produce neuroinflammation. Along with the accumulation of proteins, neuroinflammation acts as one of the triggers for neuronal damage. In this figure, the role of fatty acids in affecting the important functional pathways of microglia is summarized. Saturated fatty acids (palmitic acid, stearic acid) and omega-6 unsaturated fatty acids (arachidonic acid, linoleic acid) cause inflammatory pathway activation in microglia that is observed through hike in pro-inflammatory cytokine expression (IL-1 $\beta$, TNF-a) and activation of NF-KB pathway through TLR-4 signaling. Omega- 6 fatty acids also tend to increase neuroinflammation, which eventually leads to Tau phosphorylation and its aggregation, whereas omega-3 fatty acids influence phagocytic phenotype in microglia cells in the brain and show anti-inflammatory properties by reducing expression of pro-inflammatory cytokines (IL-1 $\beta, T N F-a)$, NF-kB pathway expression, and increased IKB expression and influence $A \beta$ and Tau phagocytosis in microglia. The ratio of omega- 6 to omega- 3 fatty acids also decides the occurrence of inflammatory pathway or phagocytic pathway depending upon their dietary ratios

NO [31, 32, 67]. Further, this is proved by p65 phosphorylation and translocation into the nucleus, confirming palmitic acid-induced activation of NF- $\mathrm{kB}$ pathway (Table 1) [31]. The presence of lipid mediators such as prostaglandins also increases inflammatory reactions, which is catalyzed by cyclooxygenase (COX). Expression of COX at the site of injury is predominant, and its expression depends upon activation of NF- $\mathrm{KB}$ cascade, which is observed in LPS as well as with saturated fatty acid-induced microglia $[66,79]$.

Table 1 The classification of fatty acids involved in microglial phagocytosis

\begin{tabular}{|c|c|c|c|}
\hline Fatty acids & Examples & Function & References \\
\hline $\begin{array}{l}\text { Saturated fatty } \\
\text { acids }\end{array}$ & $\begin{array}{l}\text { Palmitic acid (16:0) } \\
\text { Stearic acid (18:0) }\end{array}$ & $\begin{array}{l}\text { Elevation of IL-1 } \beta \text {, TNF-a } \\
\text { TLR-4 signaling pathway } \\
\text { Translocation of NF-KB in nucleus }\end{array}$ & $\begin{array}{l}\text { (Tracy, Bergqvist et al., } 2013 \text { [32]) } \\
\text { (Wang, Liu et al., } 2012[32] \text { ) }\end{array}$ \\
\hline $\begin{array}{l}\text { Omega-3 fatty } \\
\text { acids }\end{array}$ & $\begin{array}{l}\text { a-Linolenic acid } \\
(18: 3 n-3) \\
\text { Docosahexanoic } \\
\text { acid }(22: 6 n-3) \\
\text { Eicosapentanoic } \\
\text { acid }(20: 5 n-3)\end{array}$ & $\begin{array}{l}\text { Elevation of TGF- } \beta \\
\text { Increase expression of IKB } \\
\text { Inhibition of NF-KB } \\
\text { A } \beta \text { secretion (downregulate } \\
\text { amyloidogenic pathway) }\end{array}$ & $\begin{array}{l}\text { (Hjorth, Zhu et al., } 2013 \text { [53]), (De Smedt-Peyrusse, Sargueil et al., } 2008 \text { [68]), } \\
\text { (Antonietta Ajmone-Cat, Lavinia Salvatori et al., } 2012 \text { [69]), (Chen, Zhang et } \\
\text { al., } 2014 \text { [70]), (Chen, Wu et al., } 2017 \text { [71]) (Lim, Calon et al., } 2005 \text { [72]), } \\
\text { (Oksman, livonen et al., } 2006 \text { [73]) }\end{array}$ \\
\hline $\begin{array}{l}\text { Omega-6 fatty } \\
\text { acid }\end{array}$ & $\begin{array}{l}\text { Arachidonic acid } \\
(20: 4 n-6) \\
\text { Linoleic acid (18: } \\
2 n-6)\end{array}$ & $\begin{array}{l}\text { Tau phosphorylation and } \\
\text { aggregation } \\
\text { Neuroinflammation }\end{array}$ & (King, Gamblin et al., 2000), (Wilson and Binder 1997 [74]) \\
\hline \multirow[t]{2}{*}{$\begin{array}{l}\text { Omega- } 6 \text { :Omega- } \\
3 \text { fatty acids ratio }\end{array}$} & $\begin{array}{l}\text { High omega- } 6 \\
\text { concentration }\end{array}$ & Inflammatory response & $\begin{array}{l}\text { (Zhu, Wang et al., } 2016 \text { [75]), (Lafourcade, Larrieu et al., } 2011 \text { [76]), } \\
\text { (Thomazeau, Bosch-Bouju et al., } 2017 \text { [77]), (Simopoulos } 2002 \text { [78]) }\end{array}$ \\
\hline & $\begin{array}{l}\text { High Omega-3 } \\
\text { concentration }\end{array}$ & Anti-inflammatory response & \\
\hline
\end{tabular}


Unlike saturated fatty acids, polyunsaturated fatty acids having double bonds in carbon chain length have beneficial effects on the brain and eventually reduce neuroinflammation $[31,80]$. These polyunsaturated fatty acids are incorporated in the cell membrane as longchain fatty acids, which help microglia to increase phagocytosis [81]. Long-chain fatty acids increase membrane fluidity and flexibility of the cell membrane. Increase in fluidity alters the expression of receptors on membrane, disrupts receptor signaling, changes lipid raft composition, and affects the curvature of the cell membrane [82]. Reports suggested that polyunsaturated fatty acid-treated microglia express more anti-inflammatory cytokines (TGF- $\beta$, IL-10) and other phagocytic markers (CD206, Arg-1, and Ym-1). From the entire class of polyunsaturated fatty acids, omega- 3 and omega- 6 fatty acids are significant in the brain environment $[70,82,83]$. The influential role of polyunsaturated fatty acids on the brain environment is still needs to be studied (Fig. 1) [53, 83]. Diet-induced inflammation in specific areas of the brain such as the hypothalamus is also a source of excessive activation of Tau phosphorylating kinases [31, 63].

\section{Role of fatty acids in astrocytes}

Fatty acids are important component for development, differentiation, and metabolism in the body [84]. Apart from its role as a component of the cell membrane and nutrients for cells, they also act as signaling molecules in cellular pathways [85]. Astrocytes are the main source of neurotrophic factors and other metabolites that help to maintain neuronal functioning [86]. Fatty acids mainly docosahexaenoic acid (DHA) and arachidonic acid (ARA) are found to release from the cell membrane of astrocytes as a response to various stimuli including inflammation. Released DHA and ARA are then converted into lipid mediators with the help of enzymes COX (cyclooxygenase) and LOX (lipooxygenase) that regulate the inflammatory reaction [75]. Recent studies suggest that astrocytes might play a role in the free fatty acid composition of the brain in response to LPS [87]. Fatty acids are released from the cell membrane of cells depending upon phospholipase enzyme, which are specific for different groups of fatty acids, e.g., for ARA Ca ${ }^{2+}$ dependent enzyme PLA2 and for DHA $\mathrm{Ca}^{2+}$-independent enzymes CPLA2, and iPLA2 is responsible [88]. Expression of these enzymes changes the type of response, and conclusive release of DHA and ARA controls the inflammatory phase in CNS [85]. Various proinflammatory cytokines secreted by microglia are also known to be produced by astrocytes. Some proinflammatory factors, IL- $1 \beta$, TNF- $\alpha$, IL- 6 , and C1q, have the capacity to activate astrocytes leading to neuroinflammation and neuronal death [89]. IL-1 $\beta$ secreted by microglia induces $\mathrm{S} 100 \beta$, which is a calcium-binding protein in astrocytes that regulates various events such as proliferation, differentiation and also associated with elevated levels of GSK-3 $\beta$ in the neuron, which is related to Tau pathology $[90,91]$. Microglial cytokines regulate the function of astrocytes and also induce it to A1 phenotype that secretes IL-1 $\alpha$, TNF, and C1q. A1 astrocytes lose its ability to stimulate neuronal survival, synaptogenesis, and phagocytosis [92].

\section{Omega-3 fatty acids influence anti-inflammatory phenotype of microglia}

Omega- 3 fatty acids contain the first double bond at third and fourth carbon atom in their chain length and considered as essential fatty acids. The omega- 3 fatty acids are well known for its neuroprotective function and its importance in neural development in infants and children [53, 81, 93, 94]. Docosahexaenoic acid (DHA-22: 6n-3) and eicosapentaenoic acid (EPA-20: 5n-3) are the most important long-chain fatty acids found in the brain and constitute maximum part of the cell membrane [81, 95, 96]. These fatty acids are incorporated in the cell membrane as long chains of phospholipids. The main source of omega-3 fatty acids is through diet (fish oils), and they can also be synthesized from the precursor molecule $\alpha$-linolenic acid (ALA) but the rate of conversion is very low as compared to the dietary source [97]. DHA and EPA are preferentially present in cell membrane, myelin, oligodendrocytes, and nerve endings [98]. DHA and EPA are the vital factors to decide the polarity of microglia cells as proinflammatory or anti-inflammatory. DHA tends to increase the antiinflammatory phenotype of microglia by changing cell membrane composition and influencing the production of lipid mediators. Omega- 3 fatty acids also increase the phagocytosis of myelin debris and extracellular $A \beta$ peptide to clear the brain environment in $\mathrm{AD}$, which is the major cause of neuroinflammation (Fig. 2) [53, 70, 73, 99]. The levels of DHA and EPA are found to be drastically reduced with aging in the $\mathrm{AD}$ brain; this suggests the vital role of omega-3 fatty acids in the brain [98]. DHA and EPA also have a role in repressing inflammatory cytokines and factors and regulate the process of inflammation. Hjorth et al. showed in CHME3 cell upregulation of phagocytic markers such as CD206 and CD163 and downregulation of M1 markers CD40 and CD86 significantly on treatment with omega-3 fatty acid (DHA) [53, 70, 100]. It has been reported that there is a marked increase in the expression of cellular markers CD163 and CD206 and shows the direct link of DHA to a phagocytic phenotype of microglia [53]. IL-6 production decreased in a concentration-dependent manner in microglia, and there is also increased secretion of neuroprotective factor BDNF. On the basis of proven facts, it can be stated that omega-3 fatty acids are inflammation-resolving fatty acids [53, 82, 101]. 


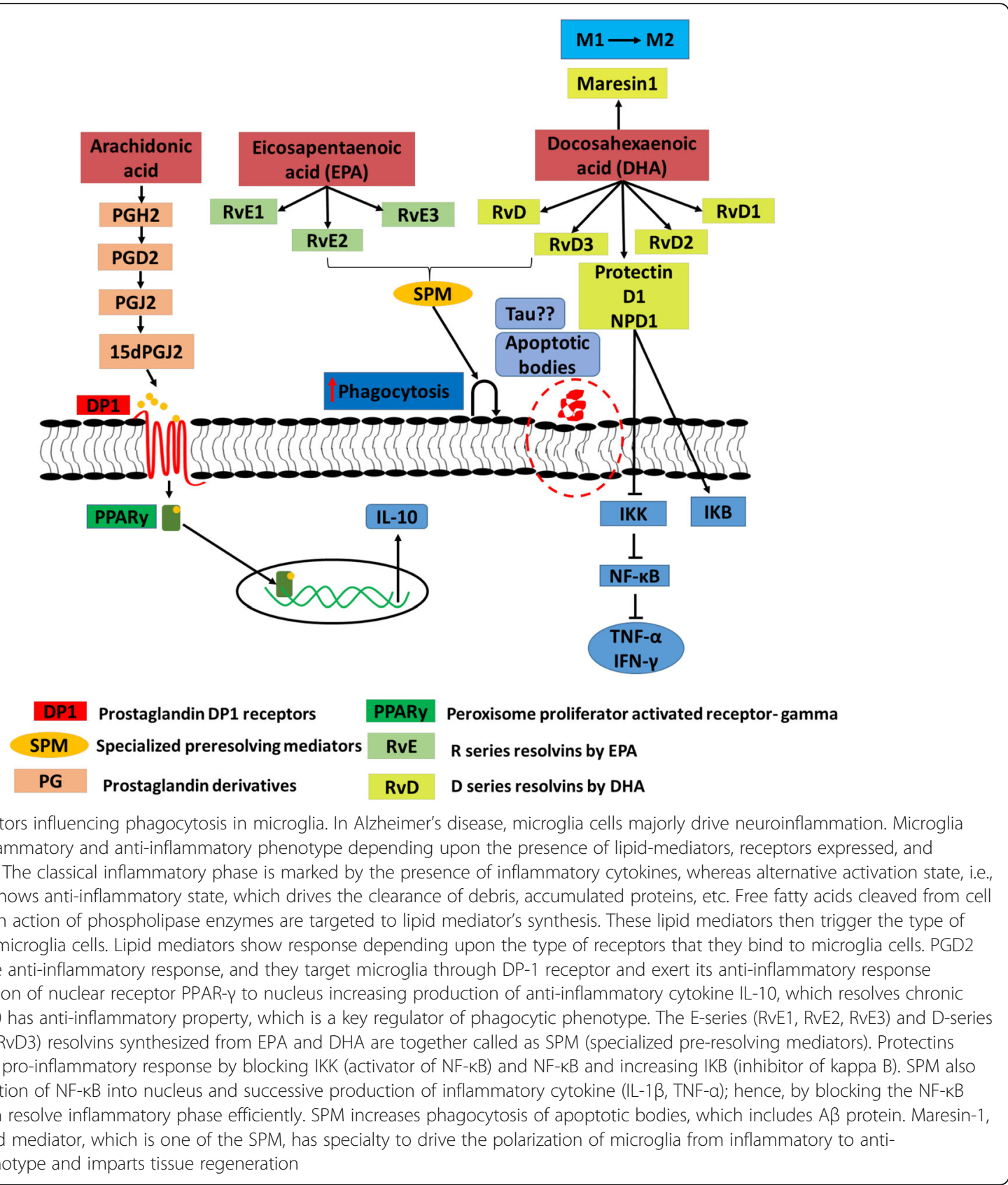

Incorporation of long-chain fatty acids into the cell membrane tends to change the lipid composition of the cell membrane and hence, affect the expression of many receptors, activation of downstream signaling molecules, etc. [102]. This also changes the fluidity of lipid bilayer. In $\mathrm{AD}, \mathrm{A} \beta$ processing is dependent on $\gamma$-secretase activity, which is present in the lipid bilayer. Thus, on the treatment of DHA or EPA, A $\beta$ processing changes the non-amyloidogenic pathway $[59,103]$. DHA has also been found to activate Akt signaling, increasing neuronal plasticity and cell survival by enhancing the production of BDNF. It also activates $\mathrm{Ca}^{2+} /$ calmodulin-dependent protein kinase (CaMKII), which is a vital signaling event in the learning and memory process [72]. A $\beta$-induced activation of Tau phosphorylating kinases like GSK-3 $\beta$ is highly downregulated by DHA and reduces Tau hyperphosphorylation and aggregation [104]. DHA induces PI-3 K/Akt survival signaling and reduces activation of Tau kinases JNK and GSK-3 $\beta$ hence, decreases $A \beta$ and induces pathology of Tau protein [105].

\section{Omega-6 fatty acids in AD}

In the brain, DHA and ARA are prime components of cell membrane and important precursors for lipid 
mediators. The brain constitutes $20 \%$ of ARA out of total fatty acid content, which is largely present in the form of phospholipids in the cell membrane [106]. DHA preferentially helps to increase memory, synaptic plasticity, learning and decrease inflammation. On the other hand, ARA acts as a mediator for endocannabinoid system, which has an important role in regulating inflammatory responses [107]. The dietary ratios of omega- 6 to omega-3 fatty acids play an important role where higher omega-6 to omega-3 fatty acids ratios in diet might affect lipid incorporation in the cell membrane and its consequences in $\mathrm{AD}$ [73]. The removal of lipids from the cell membrane is catalyzed by phospholipase $A_{2}$, which is then converted to various lipid mediators by specific enzymes that regulate inflammatory responses. Balance has to be maintained between the enzymes releasing lipids from the cell membrane and the enzymes that incorporate it into cell membrane, which is critical in neuroinflammation $[106,108]$. Besides producing lipid mediators, ARA also influences the phosphorylation of Tau protein involved in AD and their aggregation. ARA has been found to activate a number of protein kinases, which have a tendency to phosphorylate Tau protein and mediate their aggregation $[109,110]$. Protein kinase $\mathrm{C}$ (PKC) are of two types, $\mathrm{Ca}^{2+}$-dependent and $\mathrm{Ca}^{2+}$-independent; PKC are serine threonine kinase, and their zeta activity is highly enhanced by ARA [109]. Activation of PKC leads to phosphorylation of Tau by aiming leucine-rich repeat kinase-2 (LRRK2) protein increasing its aggregation. PKN- $\alpha$, a member of protein kinase superfamily, was found to be activated by ARA, which tends to phosphorylate Tau protein and also found to be colocalized with aggregated Tau protein. The free fatty acids, ARA, are also known to cause the spontaneous assembly of Tau and amyloid- $\beta$ protein in vitro even at the sub-micro molar concentration [74]. The inducible and spontaneous assembly of Tau proteins into neurofibrillary tangles is a consequence of a change in the phosphorylation state of protein; the spontaneous assembly of Tau protein in the presence of ARA indicates the same. The enzyme phospholipase A2 (PLA2), which is a $\mathrm{Ca}^{2+}$ regulated enzyme, plays an important role coupled with $\mathrm{G}$ protein signaling by inducing the cytokines. Level of arachidonic acid is regulated by PLA2; hence, its abundance is a major concern in AD. The spontaneous polymerization of Tau and amyloid- $\beta$ protein in the presence of ARA indicates the important relevance of PLA2 in AD (Fig. 3) [74].

\section{Lipid mediators drive microglial phenotype}

One of the major causes of neuroinflammation is excessive production of lipid mediators. The synthesis of lipid mediators proceeds in three stages: pre-inflammatory to pro-resolution phase followed by the final anti- inflammatory phase [111]. Fatty acids are released from the cell membrane after the action of an enzyme such as phospholipase $A_{2}$, which is a cytosolic enzyme activated by $\mathrm{Ca}^{2+}$ increase and by MAP kinase after its phosphorylation at $\mathrm{Ser}^{505}$ residue [112]. The release of ARA and DHA from the cell membrane is well-studied mechanisms; these free fatty acids are then used for the synthesis of lipid mediators, which mediate inflammatory reaction. The conversion into lipid mediators is carried out by majorly three enzymes, cyclooxygenase (COX), lipooxygenase (LOX), and cytochrome $\mathrm{P} 450$, where COX-1/2 expression decides the type of response [81]. The COX-1 enzyme is constitutively expressed in most of the body tissues while COX-2 enzymes overexpress only in inflammatory response; hence, it is considered as a marker for inflammation. The inhibition of COX-1/2 is a crucial therapeutic mechanism to reduce inflammation. Nonsteroidal anti-inflammatory drugs (NSAIDs) inhibit COX-1/2 and act as an important treatment for $\mathrm{AD}$ to reduce the inflammation. In $\mathrm{AD}$ brain, an elevated level of COX-1 expression by microglia indicates the inflammatory response, which is also observed in $A \beta$ treatment in microglia cells [106]. Inhibiting COX-2 and LOX-5 proved to inhibit the inflammatory pathway by blocking the effect of NF- $\mathrm{KB}$, with increased IL-10 concentration but decreasing the TNF- $\alpha$ and IL- 6 expression in $\mathrm{AD}$ [113]. ARA-derived lipid mediators have varied effects as it gives rise to the production of many prostaglandins (PGs) and leukotrienes (Lxs). ARA produce vital signaling molecule prostaglandin E2 (PGE2) and prostaglandin D2 (PGD2), which are synthesized from PGH2 by the enzymes PGE2 and PGD2 synthase, respectively, and their presence is abundant in glia cells mainly in microglia. PGE2 has an anti-inflammatory effect, which helps to resolve the inflammation and also helps to clear debris and accumulated proteins by phagocytosis. It is also found to increase IL-10 expression, which helps in resolving the inflammatory phase [108]. Overexpression of PGE2 during initial stages of inflammation indirectly increases the transcription of genes required for lipid mediators such as maresin (MaR), resolvins (Rv), and protectin (PD) PGD2, which adds to its anti-inflammatory effect by binding to DP1 receptor and through peroxisome proliferator-activated receptor (PPAR- $\gamma)$; a nuclear receptor is involved in increased production of IL-10. In this pathway, PGE2 first gets converted to its biologically activated form of PGJ2 by non-enzymatic dehydration. It also inhibits IKB kinase (IKK) directly, which is an activator of NF- $\mathrm{kB}$ signaling and initiates tissue repair and remodeling [113, 114]. Specialized pro-resolving mediators (SPMs), D series resolvins and $\mathrm{E}$ series resolvins $(\mathrm{Rv})$, protectins (PD), and maresin (MaR) are synthesized by LOX pathway from DHA and EPA. RvD, MaR, and PD are synthesized 


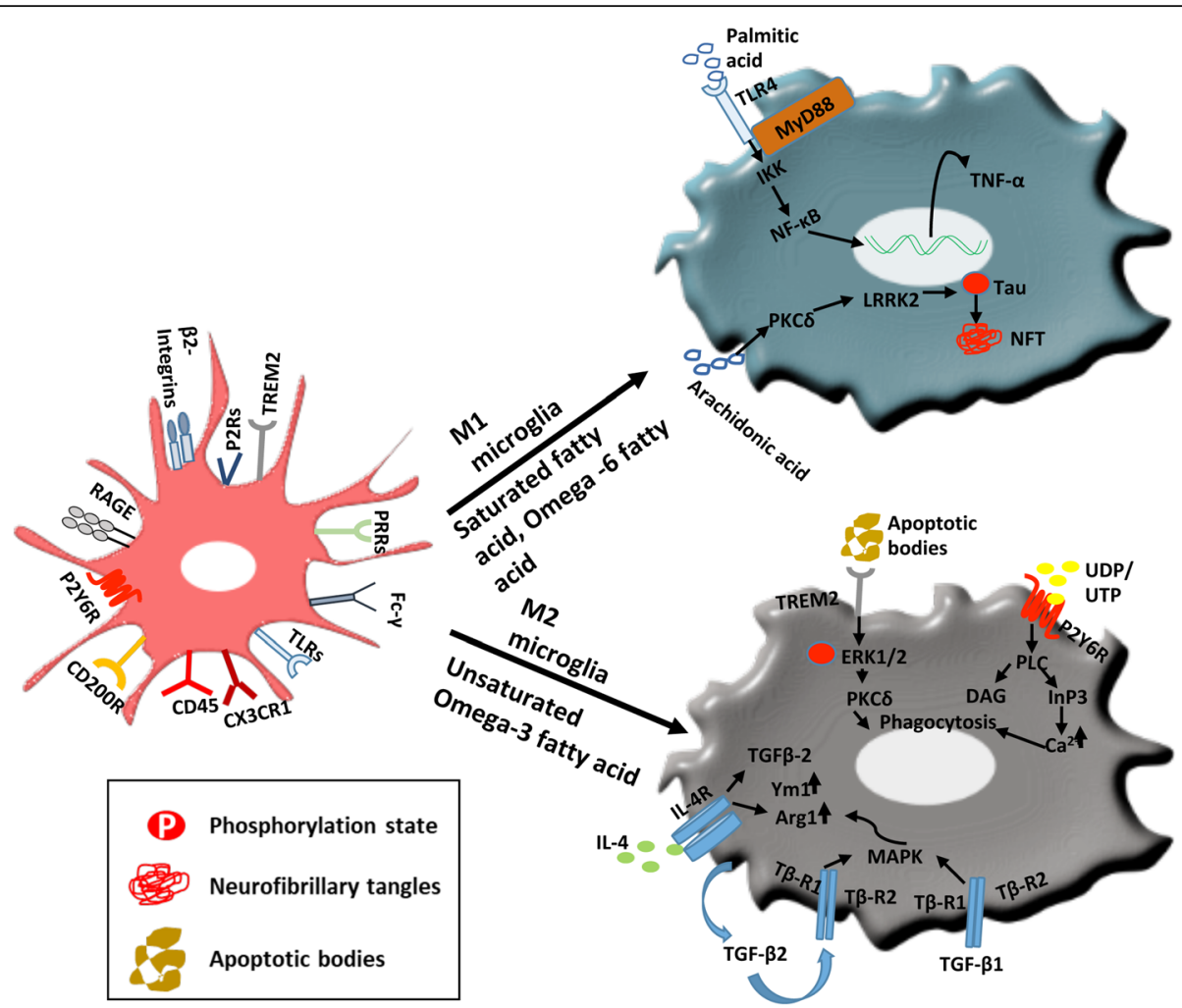

Fig. 3 Phenotypic response of microglia on dietary fatty acid exposure. Spreading of Tau between the neurons in tauopathies is a major concern to address that increases the disease progression. The aggregated species of Tau, prudentially oligomer species of misfolded aggregated Tau, show more propagation in the brain environment and found to be more toxic. The phenotype of microglia driven by omega-3 fatty acids could be used as a therapeutic strategy to prevent the propagation of extracellular Tau in tauopathies. Microglia has ramified morphology in surveillant mode, and they significantly express Fc receptors, P2Y6R, $\beta$-2 integrins, and PRRs including RAGE and TLRs. Ramified state is maintained through inhibitory signal through interaction of CD200-CD200R, CD22-CD45, and CX3CL1-CX3CR1. Saturated fatty acid (palmitic acid, stearic acid) triggers TLR-4 signaling leading to increase in pro-inflammatory cytokine production (TNF-a); omega- 6 fatty acid (arachidonic acid) activating the pathway of PKC $\delta$ causes phosphorylation of Tau increasing the aggregation of protein in cells. Thus, it favors inflammatory phenotype and also enhances aggregation of Tau in AD, whereas unsaturated omega-3 fatty acids trigger phagocytic response through TREM2 that recognizes apoptotic bodies and further activates ERK pathway to increase the clearance of apoptotic bodies. P2Y6R receptors interact with UDP released from dead neuron (act as an eat-me signal), which increases phagocytosis of debris, accumulated proteins, and pathogens. This is also indicated by increase in expression of Arginase-1 (Arg-1) and chitinase-like-3 (Ym1) and increases anti-inflammatory cytokine production (TGF- $\beta$, IL-4). Along with their anti-inflammatory properties, they also regulate wound healing through Arg-1 and Ym1. Therefore, omega-3 unsaturated fatty acids favor antiinflammatory phenotype that can mediate clearance of extracellular Tau in tauopathies

by DHA, whereas RvE is from EPA (Fig. 2) [115]. SPMs bind to cellular receptors for their functioning, e.g., RvD1 acts via binding to GPR32, RvE1 through ChemR23 orphan receptor [116]. SPM increases phagocytosis and suppresses inflammation by blocking the NF- $\mathrm{kB}$ pathway and PPAR- $\gamma$-mediated mechanism. According to lipid profiling, anti-inflammatory phenotype of microglia produces more quantity of protectins, maresin, and D-resolvins, whereas inflammatory phenotype of microglia produces more of ARA-derived proinflammatory markers $[117,118]$. Recently, the MaR1 pathway is found effective in the resolution phase. MaR1 is primarily synthesized in the inflammatory phase, and their concentration increases in the subsequent resolution phase. MaR1 along with RvE1 initiates tissue remodeling. SPMs competitively bind to COX-2 over PGs and initiate resolution phase. Therefore, an increase in dietary ratio of $\mathrm{n}-3$ fatty acids to $\mathrm{n}-6$ fatty acids provides a beneficial role in the reduction of inflammatory response. Lipid mediators, therefore, play an important role in phenotype remodeling in microglial cells and efficiently support the switching of pro-inflammatory to antiinflammatory phenotype of microglia. They also enhance the ability of anti-inflammatory cells to undergo phagocytosis where IL-10 plays a key role in the tuning function (Fig. 2) [113].

\section{Fatty acids influence differential cytokine production in microglia}

The cytokine profile of microglia depends upon the phenotype of microglia. The polarization of microglia is a significant process, which decides the fate of reaction. 
The polarization of microglia can be monitored by plasma fatty acid level, and it alters with respect to various dietary habits. Since fatty acids can cross the bloodbrain barrier through simple diffusion, their level in the plasma directly affects microglia cells. Therefore, gliosis also arises due to obesity, which triggers metabolic dysfunction [17, 35].

Different classes of fatty acids drive the polarization of microglial cells by deciding the flexibility of the cell membrane, which in turn formulates the type of receptors and a response given by cell. Long-chain saturated fatty acids polarize microglia towards the inflammatory phenotype by increasing the level of cytokine secretion critically of TNF- $\alpha$, IL-6, and IL- $1 \beta$ [31]. The secretion of these pro-inflammatory cytokines has been observed in cultured astrocytes in a dose-dependent manner [119]. Palmitic acid (PA) is the most potent candidate of all the saturated fatty acid class to cause increased expression of pro-inflammatory cytokines followed by stearic acid and lauric acid. Omega- 6 fatty acids including ARA and linoleic acid also show increased expression of the pro-inflammatory cytokine on treatment, but the levels are less as compared to palmitic acid in astrocytes [119]. In microglial cells, PA induces marked upregulation of IL- $1 \beta$, which is a key mediator of inflammatory response. IL-1 overexpression by microglia cells ensures the upregulation of IL-1 $\beta$, IL- 6 , and microglia activation. The cytokine profile favors neuronal stress and neurodegeneration. NF- $\mathrm{kB}$-mediated inflammatory responses have been observed due to the activation of TLR-4 pathway by palmitic acid. Saturated fatty acids showed its effect on TLR-4 activity by inducing changes in lipid rafts and hence activating downstream NF- $\mathrm{KB}$ inflammatory reaction. IL-6 production, on the other hand, is totally independent of NF- $\mathrm{kB}$ pathway and is not affected by omega-3 fatty acids (Fig. 3) [31].

The condition of neuroinflammation arose due to the fact that the balance between the pro-inflammatory phase and the anti-inflammatory phase is not properly maintained. Microglia could be a direct target to address, which can decrease the degree of disease. Omega3 fatty acids especially DHA have the ability to reduce the pro-inflammatory cytokines secreted by microglia $[35,69]$. Omega-3 fatty acids and their products such as neuroprotectins (PD) and resolvins (Rv) have antiinflammatory properties. DHA has been found to inhibit the significant inflammatory pathway NF- $\mathrm{KB}$ and activates pathways, which modify the LPS, and IFN- $\gamma$ induced a response. DHA also influence phosphorylation of P38 MAPK kinase, which is most important in inflammatory cytokine production and increases nuclear translocation of PPAR $\gamma$, which results in the production of anti-inflammatory cytokine IL-10. DHA also restores the level of IGF-1 that is reduced in LPS-induced reactions [120]. In conclusion, omega-3 fatty acids reduce microglial activation and aid anti-inflammatory phenotype [121].

\section{Spreading of Tau influenced by microglia}

Unusual accumulation of Tau protein in the form of neurofibrillary tangles is one of the reasons of neuroinflammation. Aberrant gliosis is, therefore, an indirect measure of accelerated Tau pathology and successive neurodegeneration. Secreted inflammatory cytokines have proved to activate astrocytes in the vicinity [122]. The excessive glial activation has the ability to modify Tau pathology by activating kinases, which have an effect on driving pathological Tau [123]. In normal conditions, Tau is bound to microtubule filaments and regulates its stability and assembly and also facilitates cargo transport through microtubules [124-126]. In order to remain bound to microtubule filaments, there is phosphorylation at serine threonine residues, which also regulates its conformational changes. Any abnormal phosphorylation alters Tau conformation, which results in detachment from microtubules [127, 128]. The free hyperphosphorylated Tau has a greater tendency to acquire beta-sheet conformation and accumulate as neurofibrillary tangles [124]. A neurofibrillary tangle gets deposited in neurons and leads to neuronal loss. With the existing data, it has been proved that these pathological Tau species spread within the neuronal network and cause propagation of Tau [38, 129-132]. The released Tau has been detected in CSF and also has the ability to be taken up by neighboring cells through various mechanisms [133-135]. After getting internalized into the cell, the abnormal aggregated Tau has the ability to induce template misfolding that proceeds to seeding effect of Tau $[45,136,137]$. Microglial activation on the other side acts as a positive regulator of Tau as secreted cytokines drive the hyperphosphorylation of Tau and its aggregation [123]. However, microglia also contributes to Tau spreading; they take up both soluble and insoluble aggregated forms of Tau. Internalized Tau can undergo by two pathways, either they undergo degradation or there is re-release of Tau species outside the cell [138-140]. The discharge of Tau is in the form of exosomes through various mechanisms [135, 141]. Microglia has the capacity to phagocytose Tau and re-released in exosomes, which would cause the spreading of Tau. Reduction in exosome synthesis can reduce Tau spreading [142]. The inflammatory response given by microglia alters Tau, independent of exosomes-mediated mechanisms. It has been proved that dietary intake of fatty acids could be effective to prevent $\mathrm{AD}$ and can act as an additional therapy for AD (Fig. 4) [102]. Dietary fatty acids especially omega- 3 fatty acids mediate antiinflammatory response in microglia by affecting the 


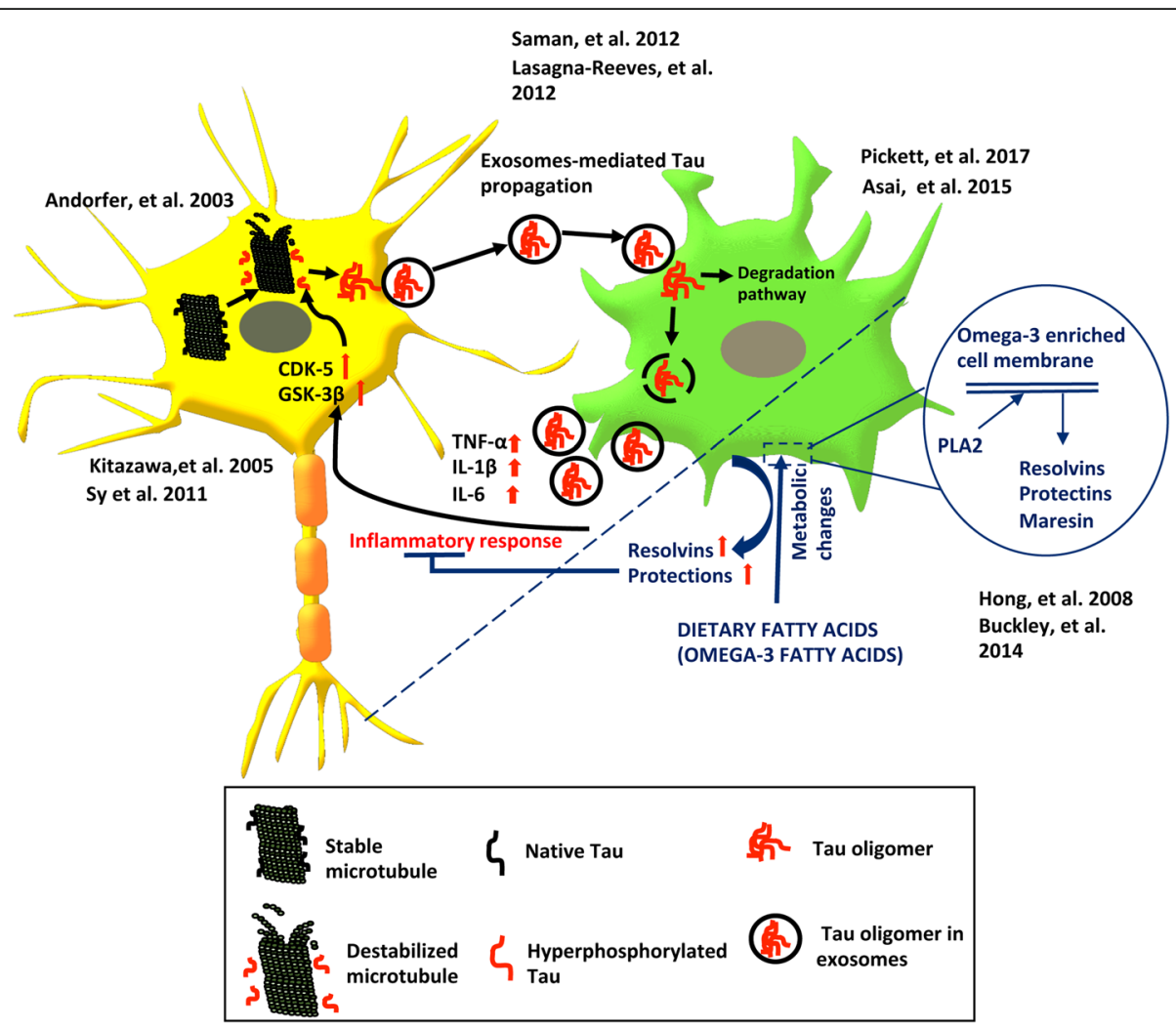

Fig. 4 Propagation of Tau mediated by microglia. Tau is a microtubule-associated protein, stabilizes microtubule, and supports cargo transport. On abnormal hyperphosphorylation, Tau protein detaches from the microtubule and aggregates in the form of oligomers to further accumulate in the form of neurofibrillary tangles inside the neuron. The aggregated Tau protein, especially oligomers, has the tendency to spread within the neuron and cause template-dependent misfolding of normal Tau protein which is called seeding effect of Tau. One of the mechanisms for the spreading of Tau is exosome-mediated spreading. Exosomes are further taken up by microglia, which can either undergo degradation pathway or can be re-released in the brain environment enhancing Tau propagation. Due to the presence of aggregated Tau protein, microglia become activated and influence the inflammatory response through cytokine secretion (IL-1 $\beta$, IL-6, TNF-a). The inflammatory cytokines enhance Tau pathology by reciprocating enhancement of expression of phosphorylation-dependent kinases CDK5 and GSK-3 3 in neuron increasing Tau hyperphosphorylation. Dietary omega-3 fatty acids repress the inflammatory response by enhancing the synthesis of lipid mediator's resolvins and protectins by microglia. We hypothesize that the lipid mediators can resolve the inflammatory phase and hence can reduce Tau pathology by decreasing expression of Tau phosphorylating kinases

production of lipid mediators such as resolvins and protectins [113] Omega-3 fatty acids therefore can be used as therapeutic strategies to reduce microglial activation that would control Tau pathology. Here, we suggest that by reducing the inflammatory response, Tau pathology can be reduced. The level to which gliosis can be controlled through dietary fatty acids especially omega-3 fatty acids is an area of research to contribute.

\section{Conclusions}

In this study, we have focused on the role of dietary fatty acids in tuning the microglial polarization. In AD-like neurodegenerative disease, inflammatory microglia is more predominant due to the accumulation of abnormal proteins. Inflammatory phenotype of microglia lacks the clearance ability, which eventually leads to excessive accumulation of protein such as $A \beta$ and Tau. According to the literature, dietary fatty acids especially omega- 3 fatty acids have the ability to affect the brain environment to a great extent, as it constitutes most of the fatty acid content of the brain. Omega-3 fatty acids, hence, can enhance the polarization of microglia towards antiinflammatory phagocytic phenotype by upregulating or downregulating expression of certain receptors on the surface of microglia changing its phenotype. They also affect the flexibility of the cell membrane that contributes to the polarization state of microglia. Of interest, the ability of microglia can be actually taken under consideration to clear the accumulated protein in $\mathrm{AD}$, which is the major concern. Propagation of Tau protein, oligomer species, and aggregated proteins, which are released outside the cells, could be engulfed by anti-inflammatory phagocytic phenotype of microglia, and their clearance will eventually reduce the propagation in Tauopathies like AD. Extracellular Tau burden induces templatedependent aggregation of healthy Tau and hence, the 
spreading of disease. Dietary fatty acids play a major role in increasing the percentage of anti-inflammatory phenotype of microglia that ultimately dominates the environment and can be used as a potential therapeutic tool to reduce the burden of accumulated protein. Another aspect is that omega- 3 fatty acids act as a competitive inhibitor of ARA to reduce the production of inflammatory lipid mediators' production. Omega-3 fatty acids hence reduce the inflammatory condition. The overall effect of omega- 3 fatty acids would help the brain environment to improve and reduce pathological conditions of AD.

\section{Abbreviations \\ AD: Alzheimer's disease; ARA: Arachidonic acid; $\mathrm{CaMKII} \mathrm{Ca}^{2+} /$ calmodulin- $^{-}$ dependent protein kinase; COX: Cyclooxygenase; DAM: Disease-associated microglia; DHA: Docosahexanoic acid; EPA: Eicosapentanoic acid; HD: Huntington's disease; IFN-Y: Interferon-Y; IKK: IKB kinase; LOX: Lipooxygenase; LRRK2: Leucine-rich repeat kinase 2; MaR: Maresin; NFTs: Neurofibrillary tangles; NO: Nitric oxide; NSAIDs: Nonsteroidal anti-inflammatory drug; PD: Parkinson's disease; PD: Protectin; PG: Prostaglandins; PHF: Paired helical filaments; PKC: Protein kinase C; PLA2: Phospholipase A2; ROS: Reactive oxygen species; Rv: Resolvins; SPM: Specialized pro-resolving mediators}

\section{Acknowledgements}

We are grateful to Chinnathambi lab members for their scientific discussions and helpful suggestions, and we highly appreciate their critical reading of the manuscript. The authors greatly acknowledge Rashmi Das for her help in critically reading the manuscript.

\section{Authors' contributions}

SD prepared the initial draft and wrote the paper. SC conceived, designed, supervised, prepared the initial draft, reviewed, edited, and wrote the paper. Both authors read and approved the final paper.

\section{Funding}

This project is supported by the in-house CSIR-National Chemical Laboratory grant MLP029526.

\section{Availability of data and materials}

This review does not contain any analyzable data. All authors cited in this paper are publicly available.

\section{Ethics approval and consent to participate}

Not applicable.

\section{Consent for publication}

Not applicable.

\section{Competing interests}

The authors declare that they have no competing interest.

Received: 7 November 2019 Accepted: 10 February 2020 Published online: 24 March 2020

\section{References}

1. Gitler AD, Dhillon P, Shorter J. Neurodegenerative disease: models, mechanisms, and a new hope. The Company of Biologists Ltd. 2017;10:499-502.

2. Ozben T, Ozben S. Neuro-inflammation and anti-inflammatory treatment options for Alzheimer's disease. Clin Biochem. 2019;72:87-89.

3. Kashyap G, Bapat D, Das D, Gowaikar R, Amritkar R, Rangarajan G, Ravindranath V, Ambika G. Synapse loss and progress of Alzheimer's disease-a network model. Sci Rep. 2019;9:6555

4. Canter RG, Penney J, Tsai L-H. The road to restoring neural circuits for the treatment of Alzheimer's disease. Nature. 2016;539:187.

5. Abeliovich A, Gitler AD. Defects in trafficking bridge Parkinson's disease pathology and genetics. Nature. 2016;539:207.
6. Bradshaw J, Saling M, Hopwood M, Anderson V, Brodtmann A. Fluctuating cognition in dementia with Lewy bodies and Alzheimer's disease is qualitatively distinct. J Neurol Neurosurg Psychiatry. 2004;75:382-7.

7. Walker M, Ayre G, Cummings J, Wesnes K, McKeith I, O'brien J, Ballard C. The clinician assessment of fluctuation and the one day fluctuation assessment scale: two methods to assess fluctuating confusion in dementia. Br J Psychiatry. 2000;177:252-6.

8. Buckner RL. Memory and executive function in aging and AD: multiple factors that cause decline and reserve factors that compensate. Neuron. 2004:44:195-208.

9. Escobar I, Xu J, Jackson CW, Perez-Pinzon MA. Altered neural networks in the Papez Circuit: implications for cognitive dysfunction after cerebral ischemia. J Alzheimers Dis. 2019:67:1-22.

10. Palop JJ, Chin J, Mucke L. A network dysfunction perspective on neurodegenerative diseases. Nature. 2006:443:768.

11. Chu D, Liu F. Pathological changes of tau related to Alzheimer's disease. ACS Chem Neurosci. 2018:10:931-44.

12. Mandelkow E-M, Mandelkow E. Biochemistry and cell biology of tau protein in neurofibrillary degeneration. Cold Spring Harbor Perspect Med. 2012;2:a006247.

13. Gao Y-L, Wang N, Sun F-R, Cao X-P, Zhang W, Yu J-T. Tau in neurodegenerative disease. Ann Transl Med. 2018;6:10.

14. De Felice FG, Velasco PT, Lambert MP, Viola K, Fernandez SJ, Ferreira ST, Klein WL. A oligomers induce neuronal oxidative stress through an $\mathrm{N}$ methyl-D-aspartate receptor-dependent mechanism that is blocked by the Alzheimer drug memantine. J Biol Chem. 2007;282:11590-601.

15. Zempel H, Thies E, Mandelkow E, Mandelkow E-M. A $\beta$ oligomers cause localized Ca2+ elevation, missorting of endogenous Tau into dendrites, Tau phosphorylation, and destruction of microtubules and spines. J Neurosci. 2010;30:11938-50

16. Gorantla NV, Chinnathambi S. Tau protein squired by molecular chaperones during Alzheimer's disease. J Mol Neurosci. 2018;66:356-68.

17. Neumann H, Kotter M, Franklin R. Debris clearance by microglia: an essential link between degeneration and regeneration. Brain. 2008;132:288-95.

18. Chen J, Zhou Y, Mueller-Steiner S, Chen L-F, Kwon H, Yi S, Mucke L, Gan L. SIRT1 protects against microglia-dependent amyloid- $\beta$ toxicity through inhibiting NF-KB signaling. J Biol Chem. 2005;280:40364-74.

19. Arcuri C, Mecca C, Bianchi R, Giambanco I, Donato R. The pathophysiological role of microglia in dynamic surveillance, phagocytosis and structural remodeling of the developing CNS. Front Mol Neurosci. 2017;10:191.

20. Tang $Y$, Le $W$. Differential roles of $M 1$ and M2 microglia in neurodegenerative diseases. Mol Neurobiol. 2016;53:1181-94.

21. Block ML, Zecca L, Hong J-S. Microglia-mediated neurotoxicity: uncovering the molecular mechanisms. Nat Rev Neurosci. 2007:8:57.

22. Zrzavy T, Hametner S, Wimmer I, Butovsky O, Weiner HL, Lassmann H. Loss of 'homeostatic' microglia and patterns of their activation in active multiple sclerosis. Brain. 2017;140:1900-13.

23. Martinez FO, Gordon S. The M1 and M2 paradigm of macrophage activation: time for reassessment. F1000 Prime Rep. 2014;6:1.

24. Ransohoff RM. A polarizing question: do M1 and M2 microglia exist? Nat Neurosci. 2016;19:987.

25. Cherry JD, Olschowka JA, O'Banion MK. Neuroinflammation and M2 microglia: the good, the bad, and the inflamed. J Neuroinflammation. 2014;11:98.

26. Davis MJ, Tsang TM, Qiu Y, Dayrit JK, Freij JB, Huffnagle GB, Olszewski MA. Macrophage M1/M2 polarization dynamically adapts to changes in cytokine microenvironments in Cryptococcus neoformans infection. MBio. 2013;4: e00264-13.

27. Franco R, Fernandez-Suarez D. Alternatively activated microglia and macrophages in the central nervous system. Prog Neurobiol. 2015;131:65-86.

28. Zhang L, Zhang J, You Z. Switching of the microglial activation phenotype is a possible treatment for depression disorder. Front Cell Neurosci. 2018;12:306.

29. Rangaraju S, Dammer EB, Raza SA, Rathakrishnan P, Xiao H, Gao T, Duong DM, Pennington MW, Lah JJ, Seyfried NT. Identification and therapeutic modulation of a pro-inflammatory subset of disease-associated-microglia in Alzheimer's disease. Mol Neurodegener. 2018;13:24.

30. Tyler K. Unique Microglia Type Associated with Restricting Development of Alzheimerâ s Disease. Cell. 2017;169(7):1276-90.

31. Wang Z, Liu D, Wang F, Liu S, Zhao S, Ling E-A, Hao A. Saturated fatty acids activate microglia via Toll-like receptor 4/NF-kB signalling. Br J Nutr. 2012;107:229-41.

32. Tracy LM, Bergqvist F, Ivanova EV, Jacobsen KT, Iverfeldt $K$. Exposure to the saturated free fatty acid palmitate alters BV-2 microglia inflammatory response. J Mol Neurosci. 2013;51:805-12. 
33. Aloisi F. Immune function of microglia. Glia. 2001;36:165-79.

34. Orihuela R, McPherson CA, Harry GJ. Microglial M1/M2 polarization and metabolic states. Br J Pharmacol. 2016;173:649-65.

35. Sarlus H, Heneka MT. Microglia in Alzheimer's disease. J Clin Invest. 2017; 127:3240-9.

36. Das R, Chinnathambi S. Microglial priming of antigen presentation and adaptive stimulation in Alzheimer's disease. Cell Mol Life Sci. 2019;1:1-14.

37. López-Valdés HE, Martínez-Coria H. The role of neuroinflammation in agerelated dementias. Rev Investig Clin. 2016;68:40-8.

38. Leyns CE, Holtzman DM. Glial contributions to neurodegeneration in tauopathies. Mol Neurodegener. 2017;12:50.

39. Kovac A, Erickson MA, Banks WA. Brain microvascular pericytes are immunoactive in culture: cytokine, chemokine, nitric oxide, and LRP-1 expression in response to lipopolysaccharide. J Neuroinflammation. 2011:8:139.

40. Heneka MT, Kummer MP, Stutz A, Delekate A, Schwartz S, Vieira-Saecker A, Griep A, Axt D, Remus A, Tzeng T-C. NLRP3 is activated in Alzheimer's disease and contributes to pathology in APP/PS1 mice. Nature. 2013;493:674

41. Ahmed Z, Cooper J, Murray TK, Garn K, McNaughton E, Clarke H, Parhizkar S, Ward MA, Cavallini A, Jackson S. A novel in vivo model of tau propagation with rapid and progressive neurofibrillary tangle pathology: the pattern of spread is determined by connectivity, not proximity. Acta Neuropathol. 2014; 127:667-83.

42. Clavaguera F, Bolmont T, Crowther RA, Abramowski D, Frank S, Probst A Fraser G, Stalder AK, Beibel M, Staufenbiel M. Transmission and spreading of tauopathy in transgenic mouse brain. Nat Cell Biol. 2009;11:909.

43. Das R, Balmik AA, Chinnathambi S. Phagocytosis of full-length Tau oligomers by Actin-remodeling of activated microglia. J Neuroinflammation. 2020;17:1-15

44. Barron M, Gartlon J, Dawson LA, Atkinson PJ, Pardon M-C. A state of delirium: deciphering the effect of inflammation on tau pathology in Alzheimer's disease. Exp Gerontol. 2017;94:103-7.

45. Frost $B$, Jacks RL, Diamond MI. Propagation of tau misfolding from the outside to the inside of a cell. J Biol Chem. 2009;284:12845-52.

46. Kitazawa M, Oddo S, Yamasaki TR, Green KN, LaFerla FM. Lipopolysaccharide-induced inflammation exacerbates tau pathology by a cyclin-dependent kinase 5-mediated pathway in a transgenic model of Alzheimer's disease. J Neurosci. 2005;25:8843-53.

47. Gorlovoy P, Larionov S, Pham TTH, Neumann H. Accumulation of tau induced in neurites by microglial proinflammatory mediators. FASEB J. 2009; 23:2502-13.

48. Pei J-J, Braak E, Braak H, Grundke-lqbal I, Iqbal K, Winblad B, Cowburn RF Localization of active forms of C-jun kinase (JNK) and p38 kinase in Alzheimer's disease brains at different stages of neurofibrillary degeneration. J Alzheimers Dis. 2001;3:41-8.

49. Metcalfe MJ, Figueiredo-Pereira ME. Relationship between tau pathology and neuroinflammation in Alzheimer's disease. Mount Sinai J Med. 2010;77: 50-8.

50. Oddo S, Caccamo A, Shepherd JD, Murphy MP, Golde TE, Kayed R, Metherate R, Mattson MP, Akbari Y, LaFerla FM. Triple-transgenic model of Alzheimer's disease with plaques and tangles: intracellular $A \beta$ and synaptic dysfunction. Neuron. 2003;39:409-21.

51. Janelsins MC, Mastrangelo MA, Park KM, Sudol KL, Narrow WC, Oddo S, LaFerla FM, Callahan LM, Federoff HJ, Bowers WJ. Chronic neuron-specific tumor necrosis factor-alpha expression enhances the local inflammatory environment ultimately leading to neuronal death in 3xTg-AD mice. Am J Pathol. 2008;173:1768-82.

52. Mastrangelo MA, Sudol KL, Narrow WC, Bowers WJ. Interferon- $\gamma$ differentially affects Alzheimer's disease pathologies and induces neurogenesis in triple transgenic-AD mice. Am J Pathol. 2009;175:2076-88.

53. Hjorth E, Zhu M, Toro VC, Vedin I, Palmblad J, Cederholm T, Freund-Levi Y, Faxen-Irving G, Wahlund L-O, Basun $\mathrm{H}$. Omega-3 fatty acids enhance phagocytosis of Alzheimer's disease-related amyloid- $\beta 42$ by human microglia and decrease inflammatory markers. J Alzheimers Dis. 2013;35:697-713.

54. Suzumura A. Neuron-microglia interaction in neuroinflammation. Curr Protein Pept Sci. 2013;14:16-20

55. Wang Y, Zhu T, Wang M, Zhang F, Zhang G, Zhao J, Zhang Y, Wu E, Li X. Icariin attenuates $M 1$ activation of microglia and $A \beta$ plaque accumulation in the hippocampus and prefrontal cortex by up-regulating PPARy in restraint/ isolation-stressed APP/PS1 mice. Front Neurosci. 2019;13:291.
56. Toscano R, Millan-Linares MC, Lemus-Conejo A, Claro C, Sanchez-Margalet V, Montserrat-de la Paz S: Postprandial triglyceride-rich lipoproteins promote M1/M2 microglia polarization in a fatty-acid-dependent manner. J Nutr Biochem 2020, 75:108248.

57. Manchikalapudi AL, Chilakala RR, Kalia K, Sunkaria A. Evaluating the role of microglial cells in clearance of A from Alzheimer's brain. ACS Chem Neurosci. 2019;10(3):1149.

58. Pfrieger F. Cholesterol homeostasis and function in neurons of the central nervous system. Cell Mol Life Sci CMLS. 2003;60:1158-71.

59. Hartmann T, Kuchenbecker J, Grimm MO. Alzheimer's disease: the lipid connection. J Neurochem. 2007;103:159-70.

60. Freund Levi $Y$, Vedin I, Cederholm T, Basun H, Faxén Irving G, Eriksdotter M, Hjorth E, Schultzberg M, Vessby B, Wahlund LO. Transfer of omega-3 fatty acids across the blood-brain barrier after dietary supplementation with a docosahexaenoic acid-rich omega-3 fatty acid preparation in patients with Alzheimer's disease: the $O$ meg $A D$ study. J Intern Med. 2014;275:428-36.

61. Guillemot-Legris O, Masquelier J, Everard A, Cani PD, Alhouayek M, Muccioli GG. High-fat diet feeding differentially affects the development of inflammation in the central nervous system. J Neuroinflammation. 2016;13:206.

62. Guillemot-Legris O, Muccioli GG. Obesity-induced neuroinflammation: beyond the hypothalamus. Trends Neurosci. 2017:40:237-53.

63. Valdearcos M, Robblee MM, Benjamin DI, Nomura DK, XU AW, Koliwad SK. Microglia dictate the impact of saturated fat consumption on hypothalamic inflammation and neuronal function. Cell Rep. 2014;9:2124-38.

64. Nadjar A. Role of metabolic programming in the modulation of microglia phagocytosis by lipids. Prostaglandins Leukot Essent Fat Acids. 2018;135:63-73.

65. Ng Y-W, Say Y-H. Palmitic acid induces neurotoxicity and gliatoxicity in SHSY5Y human neuroblastoma and T98G human glioblastoma cells. PeerJ. 2018;6:e4696.

66. Lee JY, Sohn KH, Rhee SH, Hwang D. Saturated fatty acids, but not unsaturated fatty acids, induce the expression of cyclooxygenase-2 mediated through Toll-like receptor 4. J Biol Chem. 2001;276:16683-9.

67. Dumas JA, Bunn JY, Nickerson J, Crain Kl, Ebenstein DB, Tarleton EK, Makarewicz J, Poynter ME, Kien CL. Dietary saturated fat and monounsaturated fat have reversible effects on brain function and the secretion of pro-inflammatory cytokines in young women. Metabolism. 2016:65:1582-8

68. De Smedt-Peyrusse V, Sargueil F, Moranis A, Harizi H, Mongrand S, Layé S. Docosahexaenoic acid prevents lipopolysaccharide-induced cytokine production in microglial cells by inhibiting lipopolysaccharide receptor presentation but not its membrane subdomain localization. J Neurochem. 2008;105(2):296-307.

69. Antonietta Ajmone-Cat M, Lavinia Salvatori M, De Simone R, Mancini M, Biagioni S, Bernardo A, Cacci E, Minghetti L. Docosahexaenoic acid modulates inflammatory and antineurogenic functions of activated microglial cells. J Neurosci Res. 2012;90:575-87.

70. Chen S, Zhang H, Pu H, Wang G, Li W, Leak RK, Chen J, Liou AK, Hu X: n-3 PUFA supplementation benefits microglial responses to myelin pathology. Sci Rep 2014; 4:7458.

71. Chen X, Wu S, Chen C, Xie B, Fang Z, Hu W, Chen J, Fu H, He H. Omega-3 polyunsaturated fatty acid supplementation attenuates microglial-induced inflammation by inhibiting the HMGB1/TLR4/NF-KB pathway following experimental traumatic brain injury. J Neuroinflammation. 2017;14(1).

72. Calon F, Lim GP, Morihara T, Yang F, Ubeda O, Salem N Jr, Frautschy SA, Cole GM. Dietary n-3 polyunsaturated fatty acid depletion activates caspases and decreases NMDA receptors in the brain of a transgenic mouse model of Alzheimer's disease. Eur J Neurosci. 2005;22:617-26.

73. Oksman $M$, livonen $H$, Hogyes $E$, Amtul $Z$, Penke B, Leenders I, Broersen L, Lütjohann D, Hartmann T, Tanila H. Impact of different saturated fatty acid, polyunsaturated fatty acid and cholesterol containing diets on beta-amyloid accumulation in APP/PS1 transgenic mice. Neurobiol Dis. 2006;23:563-72.

74. Wilson DM, Binder LI. Free fatty acids stimulate the polymerization of tau and amyloid beta peptides. In vitro evidence for a common effector of pathogenesis in Alzheimer's disease. American J Pathol. 1997;150:2181.

75. Zhu M, Wang X, Hjorth E, Colas RA, Schroeder L, Granholm A-C, Serhan CN, Schultzberg M. Pro-resolving lipid mediators improve neuronal survival and increase A 42 phagocytosis. Mol Neurobiol. 2016;53:2733-49.

76. Lafourcade M, Larrieu T, Mato S, Duffaud A Sepers M, Matias I, De SmedtPeyrusse V, Labrousse VF, Bretillon L, Matute C, Rodríguez-Puertas R, Layé S, 
Manzoni OJ. Nutritional omega-3 deficiency abolishes endocannabinoidmediated neuronal functions. Nat Neurosci. 2011;14(3):345-350.

77. Thomazeau A, Bosch-Bouju C, Manzoni O, Layé S. Nutritional n-3 PUFA deficiency abolishes endocannabinoid gating of hippocampal long-term potentiation. Cereb Cortex. 2017;27:2571-79.

78. Simopoulos AP. Omega-3 fatty acids in inflammation and autoimmune diseases. J Am Coll Nutr. 2002;21:495-505.

79. Badshah H, Ali T, Kim MO. Osmotin attenuates LPS-induced neuroinflammation and memory impairments via the TLR4/NFKB signaling pathway. Sci Rep. 2016;6:24493

80. Button EB, Mitchell AS, Domingos MM, Chung JHJ, Bradley RM, Hashemi A, Marvyn PM, Patterson AC, Stark KD, Quadrilatero J. Microglial cell activation increases saturated and decreases monounsaturated fatty acid content, but both lipid species are proinflammatory. Lipids. 2014;49:305-16.

81. Bazinet RP, Layé S. Polyunsaturated fatty acids and their metabolites in brain function and disease. Nat Rev Neurosci. 2014;15:771.

82. Laye S, Nadjar A, Joffre C, Bazinet RP. Anti-inflammatory effects of omega-3 fatty acids in the brain: physiological mechanisms and relevance to pharmacology. Pharmacol Rev. 2018;70:12-38.

83. Chhor V, Le Charpentier T, Lebon S, Oré M-V, Celador IL, Josserand J, Degos $V$, Jacotot E, Hagberg H, Sävman K. Characterization of phenotype markers and neuronotoxic potential of polarised primary microglia in vitro. Brain Behav Immun. 2013;32:70-85.

84. Dietschy JM. Central nervous system: cholesterol turnover, brain development and neurodegeneration. Biol Chem. 2009:390:287-93.

85. Aizawa F, Nishinaka T, Yamashita T, Nakamoto K, Kurihara T, Hirasawa A, Kasuya F, Miyata A, Tokuyama S. GPR40/FFAR1 deficient mice increase noradrenaline levels in the brain and exhibit abnormal behavior. J Pharmacol Sci. 2016;132:249-54.

86. Kang J, Rivest S. Lipid metabolism and neuroinflammation in Alzheimer's disease: a role for liver $X$ receptors. Endocr Rev. 2012;33:715-46.

87. Nakamoto K, Nishinaka T, Sato N, Aizawa F, Yamashita T, Mankura M, Koyama Y, Kasuya F, Tokuyama S. The activation of supraspinal GPR40/FFA1 receptor signalling regulates the descending pain control system. $\mathrm{Br} J$ Pharmacol. 2015;172:1250-62.

88. Rosa AO, Rapoport SI. Intracellular-and extracellular-derived Ca2+ influence phospholipase A2-mediated fatty acid release from brain phospholipids. Biochimica et Biophysica Acta (BBA)-Mol Cell Biol Lipids. 2009:1791:697-705.

89. Jacobs AH, Tavitian B, Consortium I. Noninvasive molecular imaging of neuroinflammation. J Cereb Blood Flow Metab. 2012;32:1393-415.

90. Brozzi F, Arcuri C, Giambanco I, Donato R: S100B protein regulates astrocyte shape and migration via interaction with Src kinase implications for astrocyte development, activation, and tumor growth. J Biol Chem 2009, 284:8797-8811.

91. Esposito G, Scuderi C, Lu J, Savani C, De Filippis D, luvone T, Steardo L Jr, Sheen V, Steardo L. S100B induces tau protein hyperphosphorylation via Dickopff-1 up-regulation and disrupts the Wnt pathway in human neural stem cells. J Cell Mol Med. 2008;12:914-27.

92. Aizawa F, Nishinaka T, Yamashita T, Nakamoto K, Koyama Y, Kasuya F, Tokuyama S. Astrocytes release polyunsaturated fatty acids by lipopolysaccharide stimuli. Biol Pharm Bull. 2016;39:1100-6.

93. Dyall SC. Long-chain omega-3 fatty acids and the brain: a review of the independent and shared effects of EPA, DPA and DHA. Front Aging Neurosci. 2015;7:52.

94. Innis SM. Omega-3 fatty acids and neural development to 2 years of age: do we know enough for dietary recommendations? J Pediatr Gastroenterol Nutr. 2009:48:S16-24.

95. Dunstan J, Roper J, Mitoulas L, Hartmann P, Simmer K, Prescott S. The effect of supplementation with fish oil during pregnancy on breast milk immunoglobulin A, soluble CD14, cytokine levels and fatty acid composition. Clin Exp Allergy. 2004:34:1237-42.

96. Fang G, Shi B, Wu K, Chen S, Gao X, Xiao S, Kang JX, Li W, Huang R. The protective role of endogenous $n-3$ polyunsaturated fatty acids in Tau Alzheimer's disease mouse model. Int J Neurosci. 2019;129:325-36.

97. Gibson R, Neumann M, Lien E, Boyd K, Tu W. Docosahexaenoic acid synthesis from alpha-linolenic acid is inhibited by diets high in polyunsaturated fatty acids. Prostaglandins Leukotrienes Essential Fatty Acids (PLEFA). 2013;88:139-46.

98. Thomas J, Thomas C, Radcliffe J, Itsiopoulos C. Omega-3 fatty acids in early prevention of inflammatory neurodegenerative disease: a focus on Alzheimer's disease. Biomed Res Int. 2015;2015:1.
99. Dong Y, Xu M, Kalueff AV, Song C. Dietary eicosapentaenoic acid normalizes hippocampal omega-3 and 6 polyunsaturated fatty acid profile, attenuates glial activation and regulates BDNF function in a rodent model of neuroinflammation induced by central interleukin-1 $\beta$ administration. Eur J Nutr. 2018:57:1781-91.

100. Gordon S. Phagocytosis: an immunobiologic process. Immunity. 2016;44: $463-75$.

101. Perea JR, Llorens-Martín M, Ávila J, Bolós M. The role of microglia in the spread of tau: relevance for tauopathies. Front Cell Neurosci. 2018;12:172.

102. Green KN, Martinez-Coria H, Khashwji H, Hall EB, Yurko-Mauro KA, Ellis L, LaFerla FM. Dietary docosahexaenoic acid and docosapentaenoic acid ameliorate amyloid- $\beta$ and tau pathology via a mechanism involving presenilin 1 levels. J Neurosci. 2007:27:4385-95.

103. Cole GM, Frautschy SA. DHA may prevent age-related dementia. J Nutr. 2010;140:869-74.

104. Resende R, Ferreiro E, Pereira C, Oliveira CR. ER stress is involved in $A \beta$ induced GSK-3 $\beta$ activation and tau phosphorylation. J Neurosci Res. 2008;86: 2091-9.

105. Ma Q-L, Yang F, Rosario ER, Ubeda OJ, Beech W, Gant DJ, Chen PP, Hudspeth B, Chen C, Zhao Y. $\beta$-amyloid oligomers induce phosphorylation of tau and inactivation of insulin receptor substrate via c-Jun $\mathrm{N}$-terminal kinase signaling: suppression by omega-3 fatty acids and curcumin. J Neurosci. 2009;29:9078-89.

106. Thomas MH, Pelleieux S, Vitale N, Olivier JL. Dietary arachidonic acid as a risk factor for age-associated neurodegenerative diseases: potential mechanisms. Biochimie. 2016;130:168-77.

107. Piomelli D, Sasso O. Peripheral gating of pain signals by endogenous lipid mediators. Nat Neurosci. 2014;17:164

108. Das UN. Arachidonic acid and other unsaturated fatty acids and some of their metabolites function as endogenous antimicrobial molecules: a review. J Adv Res. 2018;11:57-66.

109. KOCHS G, HUMMEL R, MEYER D, HUG H, MARMÉ D, SARRE TF. Activation and substrate specificity of the human protein kinase $C a$ and $\zeta$ isoenzymes. Eur J Biochem. 1993;216:597-606.

110. Mukai $\mathrm{H}$. The structure and function of PKN, a protein kinase having a catalytic domain homologous to that of PKC. J Biochem. 2003;133:17-27.

111. Whittington RA, Planel $E$, Terrando N. Impaired resolution of inflammation in Alzheimer's disease: a review. Front Immunol. 2017;8:1464.

112. Sun GY, Shelat PB, Jensen MB, He Y, Sun AY, Simonyi A. Phospholipases A2 and inflammatory responses in the central nervous system. NeuroMolecular Med. 2010;12:133-48.

113. Buckley CD, Gilroy DW, Serhan CN. Proresolving lipid mediators and mechanisms in the resolution of acute inflammation. Immunity. 2014;40: $315-27$.

114. Horrocks LA, Farooqui AA. Docosahexaenoic acid in the diet: its importance in maintenance and restoration of neural membrane function. Prostaglandins Leukot Essent Fat Acids. 2004;70:361-72.

115. Zhang MJ, Spite M. Resolvins: anti-inflammatory and proresolving mediators derived from omega-3 polyunsaturated fatty acids. Annu Rev Nutr. 2012;32: 203-27.

116. Serhan CN, Chiang N. Resolution phase lipid mediators of inflammation: agonists of resolution. Curr Opin Pharmacol. 2013;13:632-40.

117. Dalli J, Serhan CN. Specific lipid mediator signatures of human phagocytes: microparticles stimulate macrophage efferocytosis and pro-resolving mediators. Blood. 2012;120:e60-72.

118. Joffre C, Rey C, Layé S. N-3 polyunsaturated fatty acids and the resolution of neuroinflammation. Front Pharmacol. 2019;10:1.

119. Gupta S, Knight AG, Gupta S, Keller JN, Bruce-Keller AJ. Saturated long-chain fatty acids activate inflammatory signaling in astrocytes. J Neurochem. 2012; 120:1060-71.

120. Mita T, Mayanagi T, Ichijo H, Fukumoto K, Otsuka K, Sakai A, Sobue K. Docosahexaenoic acid promotes axon outgrowth by translational regulation of tau and collapsin response mediator protein 2 expression. J Biol Chem. 2016:291:4955-65.

121. Chen X, Chen C, Fan S, Wu S, Yang F, Fang Z, Fu H, Li Y. Omega-3 polyunsaturated fatty acid attenuates the inflammatory response by modulating microglia polarization through SIRT1-mediated deacetylation of the HMGB1/NF-KB pathway following experimental traumatic brain injury. J Neuroinflammation. 2018;15:116.

122. Lull ME, Block ML. Microglial activation and chronic neurodegeneration. Neurotherapeutics. 2010;7:354-65. 
123. Von Bernhardi R, Eugenín-von Bernhardi L, Eugenín J. Microglial cell dysregulation in brain aging and neurodegeneration. Front Aging Neurosci. 2015;7:124.

124. Witman GB, Cleveland DW, Weingarten MD, Kirschner MW. Tubulin requires tau for growth onto microtubule initiating sites. Proc Natl Acad Sci. 1976;73: 4070-4.

125. Morris M, Maeda S, Vossel K, Mucke L. The many faces of tau. Neuron. 2011; 70:410-26.

126. Trinczek B, Ebneth A, Mandelkow E, Mandelkow E. Tau regulates the attachment/detachment but not the speed of motors in microtubuledependent transport of single vesicles and organelles. J Cell Sci. 1999;112: 2355-67.

127. Spires-Jones TL, Stoothoff WH, de Calignon A, Jones PB, Hyman BT. Tau pathophysiology in neurodegeneration: a tangled issue. Trends Neurosci. 2009;32:150-9.

128. Arendt T, Stieler JT, Holzer M. Tau and tauopathies. Brain Res Bull. 2016;126: 238-92.

129. Guo JL, Lee VM. Cell-to-cell transmission of pathogenic proteins in neurodegenerative diseases. Nat Med. 2014;20:130

130. Polymenidou M, Cleveland DW. Prion-like spread of protein aggregates in neurodegeneration. J Exp Med. 2012;209:889-93.

131. Jucker M, Walker LC. Self-propagation of pathogenic protein aggregates in neurodegenerative diseases. Nature. 2013;501:45.

132. Sonawane SK, Chinnathambi S. Prion-like propagation of post-translationally modified tau in Alzheimer's disease: a hypothesis. J Mol Neurosci. 2018;65: 480-90.

133. Kim W, Lee S, Jung C, Ahmed A, Lee G, Hall GF. Interneuronal transfer of human tau between Lamprey central neurons in situ. J Alzheimers Dis. 2010;19:647-64

134. Fitzner D, Schnaars M, van Rossum D, Krishnamoorthy G, Dibaj P, Bakhti M, Regen T, Hanisch U-K, Simons M. Selective transfer of exosomes from oligodendrocytes to microglia by macropinocytosis. J Cell Sci. 2011;124:447-58.

135. Merezhko M, Brunello CA, Yan X, Vihinen H, Jokitalo E, Uronen R-L, Huttunen HJ. Secretion of Tau via an unconventional non-vesicular mechanism. Cell Rep. 2018;25:2027-35 e2024.

136. Guo JL, Lee VM-Y. Seeding of normal Tau by pathological Tau conformers drives pathogenesis of Alzheimer-like tangles. J Biol Chem. 2011;286:15317-31.

137. Holmes BB, Furman JL, Mahan TE, Yamasaki TR, Mirbaha H, Eades WC, Belaygorod L, Cairns NJ, Holtzman DM, Diamond MI. Proteopathic tau seeding predicts tauopathy in vivo. Proc Natl Acad Sci. 2014;111:E4376-85.

138. Wu JW, Herman M, Liu L, Simoes S, Acker CM, Figueroa H, Steinberg Jl, Margittai M, Kayed R, Zurzolo C. Small misfolded Tau species are internalized via bulk endocytosis and anterogradely and retrogradely transported in neurons. J Biol Chem. 2013;288:1856-70.

139. Bolós M, Llorens-Martín M, Jurado-Arjona J, Hernández F, Rábano A, Avila J. Direct evidence of internalization of tau by microglia in vitro and in vivo. J Alzheimers Dis. 2016:50:77-87.

140. Luo W, Liu W, Hu X, Hanna M, Caravaca A, Paul SM. Microglial internalization and degradation of pathological tau is enhanced by an antitau monoclonal antibody. Sci Rep. 2015;5:11161.

141. Saman S, Kim W, Raya M, Visnick Y, Miro S, Saman S, Jackson B, McKee AC, Alvarez VE, Lee NC. Exosome-associated tau is secreted in tauopathy models and is selectively phosphorylated in cerebrospinal fluid in early Alzheimer disease. J Biol Chem. 2012;287:3842-9.

142. Shafiei SS, Guerrero-Muñoz MJ, Castillo-Carranza DL. Tau oligomers: cytotoxicity, propagation, and mitochondrial damage. Front Aging Neurosci. 2017;9:83.

\section{Publisher's Note}

Springer Nature remains neutral with regard to jurisdictional claims in published maps and institutional affiliations.

Ready to submit your research? Choose BMC and benefit from:

- fast, convenient online submission

- thorough peer review by experienced researchers in your field

- rapid publication on acceptance

- support for research data, including large and complex data types

- gold Open Access which fosters wider collaboration and increased citations

- maximum visibility for your research: over $100 \mathrm{M}$ website views per year

At BMC, research is always in progress.

Learn more biomedcentral.com/submissions 